OPEN ACCESS

Approved by:

Frontiers in Bioengineering,

Frontiers Media SA, Switzerland

${ }^{*}$ Correspondence:

Michael F. Eckerstorfer michael.eckerstorfer@

umweltbundesamt.at

Specialty section:

This article was submitted to

Biosafety and Biosecurity,

a section of the journal

Frontiers in Bioengineering and

Biotechnology

Received: 10 April 2019

Accepted: 11 April 2019

Published: 01 May 2019

Citation:

Eckerstorfer MF, Dolezel M

Heissenberger A, Miklau M,

Reichenbecher W, Steinbrecher RA and Waßmann F (2019) Corrigendum:

An EU Perspective on Biosafety

Considerations for Plants Developed

by Genome Editing and Other

New Genetic Modification

Techniques (nGMs)

Front. Bioeng. Biotechnol. 7:90

doi: 10.3389/fbioe.2019.00090

\section{Corrigendum: An EU Perspective on Biosafety Considerations for Plants Developed by Genome Editing and Other New Genetic Modification Techniques (nGMs)}

\author{
Michael F. Eckerstorfer ${ }^{1 *}$, Marion Dolezel ${ }^{1}$, Andreas Heissenberger ${ }^{1}$, Marianne Miklau ${ }^{1}$, \\ Wolfram Reichenbecher ${ }^{2}$, Ricarda A. Steinbrecher ${ }^{3}$ and Friedrich Waßmann ${ }^{2}$ \\ ${ }^{1}$ Department Landuse \& Biosafety, Environment Agency Austria, Vienna, Austria, ${ }^{2}$ Department GMO Regulation, Biosafety, \\ Federal Agency for Nature Conservation, Bonn, Germany, ${ }^{3}$ EcoNexus, Oxford, United Kingdom
}

Keywords: new genetic modification techniques (nGM), genome editing, CRISPR/Cas, plant modification, biosafety, risk assessment

\section{A Corrigendum on}

An EU Perspective on Biosafety Considerations for Plants Developed by Genome Editing and Other New Genetic Modification Techniques (nGMs)

by Eckerstorfer, M. F., Dolezel, M., Heissenberger, A., Miklau, M., Reichenbecher, W., Steinbrecher, R. A., et al. (2019). Front. Bioeng. Biotechnol. 7:31. doi: 10.3389/fbioe.2019.00031

Marion Dolezel and Marianne Miklau were not included as authors in the published article. The corrected Author Contributions Statement appears below. The authors apologize for this error and state that this does not change the scientific conclusions of the article in any way. The original article has been updated.

\section{AUTHOR CONTRIBUTIONS}

ME conducted the study and drafted the manuscript. MD and MM contributed to data acquisition and analysis. AH, WR, RS, and FW contributed to the study design and implementation and edited the manuscript. All authors read and approved the manuscript for publication.

Copyright $\odot 2019$ Eckerstorfer, Dolezel, Heissenberger, Miklau, Reichenbecher, Steinbrecher and Waßmann. This is an openaccess article distributed under the terms of the Creative Commons Attribution License (CC BY). The use, distribution or reproduction in other forums is permitted, provided the original author(s) and the copyright owner(s) are credited and that the original publication in this journal is cited, in accordance with accepted academic practice. No use, distribution or reproduction is permitted which does not comply with these terms. 